\title{
TSUNAMI HAZARDS: FLOW RESISTANCE AND IMPACT MITIGATION BY COASTAL GREEN BELTS
}

\author{
T.D.H.M. Hemanthi ${ }^{1 *}$, A.H.R. Ratnasooriya ${ }^{1}$ and S.S.L. Hettiarachchi ${ }^{1}$ \\ ${ }^{1}$ Department of Civil Engineering, University of Moratuwa, Katubedda, Sri Lanka \\ E-mail-harini999@gmail.com*, Tel-++ 94771702417
}

\begin{abstract}
In the aftermath of the Indian Ocean Tsunami, the protection offered by coastal vegetation became evident in many countries affected and the role of coastal green belts in mitigating tsunami impacts has now been clearly recognized. Coastal green belts also attract attention as an environmental friendly and cost effective measure of impact mitigation. In this research, attention was concentrated on expanding the preliminary experimental on the resistance offered by coastal vegetation to tsunami overland flow, to determine the energy dissipation characteristics in detail, and to assess the effectiveness of coastal green belts in tsunami impact mitigation. Detailed experimental studies were conducted in which the vegetation was represented by geometrically similar small scale models. The effectiveness of coastal green belts was assessed by the percentage energy reduction for various forms of vegetation. Reduction levels in the range up to $30 \%$ were obtained in the experiments indicating the possibility of achieving significant levels of energy reduction of tsunami inundation by coastal green belts. The reliance of the level of inundation reduction on the level of energy dissipation was also investigated.
\end{abstract}

Keywords: Tsunami, Hazards, Mitigation, Coastal, Greenbelts

\section{INTRODUCTION}

Sri Lanka was unfamiliar with major natural hazards such as tsunamis until 2004 when the Indian Ocean Tsunami (IOT) on December 26 severely damaged the coastal areas causing a large number of casualties and property damage. The IOT in 2004, subsequent tsunami alerts in 2005 and 2007 as well as the historical records of tsunami events in the past have highlighted the exposure of Sri Lanka to such hazards and the need of developing appropriate impact mitigation measures has clearly been identified.

Following the IOT disaster, the protection offered by coastal vegetation became evident in many countries affected and the role of coastal green belts in mitigating tsunami impacts has now been clearly recognized. Coastal green belts also attract attention as an environmental friendly and cost effective measure of impact mitigation. The development and utilization of coastal green belts would thus be effective as an impact mitigation measure for such infrequent hazards like tsunamis. In this research, attention was concentrated on expanding the preliminary experimental studies on the resistance offered by coastal vegetation to tsunami overland flow and to determine the energy dissipation characteristics in detail, in order to assess the effectiveness of coastal green belts in tsunami impact mitigation.

\section{ENERGY DISSIPATION DUE TO RESISTANCE OFFERED BY COASTAL VEGETATION}

The flow through vegetation can be considered as a flow around non-streamlined solid bodies from a hydraulic engineering point of view. In such flow both drag and inertia forces contribute to the resistance offered by solid bodies. In the tsunami induced overland flow caused by long waves of large periods, the drag force is dominant in comparison to the inertia force (Tanaka et al, 2007) and it can be considered that the energy dissipation of flow through vegetation is mainly caused by drag resistance.

Proceedings of the $15^{\text {th }}$ International Forestry and Environment Symposium, 26-27 November 2010.

Published by Department of Forestry and Environmental Science, University of Sri Jayewardenepura, Sri Lanka. 
The drag resistance $F$ can be defined as,

$$
F=\frac{1}{2} \rho C_{D} A U^{2}
$$

Where, $\quad \rho=$ Density of fluid

$C_{D}=$ Drag coefficient

$A=$ Projected area of solid body

$U=$ Velocity of flow

The drag coefficient depends on the shape of the body and the characteristics of the wake formed by the separation of flow around the solid body. The variation of drag coefficient can be expressed in terms of the Reynolds number $R e$, which for a circular body can be expressed as,

$$
R e=\frac{U D}{v}
$$

Where, $\quad \mathrm{D}=$ Diameter

$$
\mathrm{v}=\text { Coefficient of kinematic viscosity of fluid }
$$

\section{DRAG RESISTANCE AND VEGETATION CHARACTERISTICS}

In a flow through group of solid bodies, as the wakes formed by upstream bodies disturbed by downstream bodies the total resistance would be influenced by the number of bodies and the distribution pattern of bodies. Thus the drag resistance offered by vegetation would depend on the characteristics of individual plants as well as the vegetation as a whole, namely density/spacing, extent and distribution pattern and the plant species as illustrated in Figure 1. Based on field studies, three main components of a plant structure aerial root system, stem and branch structure representing various degree of resistance have been identified (Ratnasooriya et al, 2008). The influence of these three components has been considered together with depth of inundation, by identifying vegetation in four categories as indicated in Table 1 .

Table 1: Categories of Vegetation

\begin{tabular}{|c|c|c|c|}
\hline \multirow{2}{*}{ Category } & \multicolumn{3}{|c|}{ Inundation } \\
\cline { 2 - 4 } & Aerial root system & Stem & Branch Structure \\
\hline I & No & Yes & No \\
\hline II & No & Yes & Yes \\
\hline III & Yes & Yes & Yes \\
\hline IV & Yes & Yes & \\
\hline
\end{tabular}




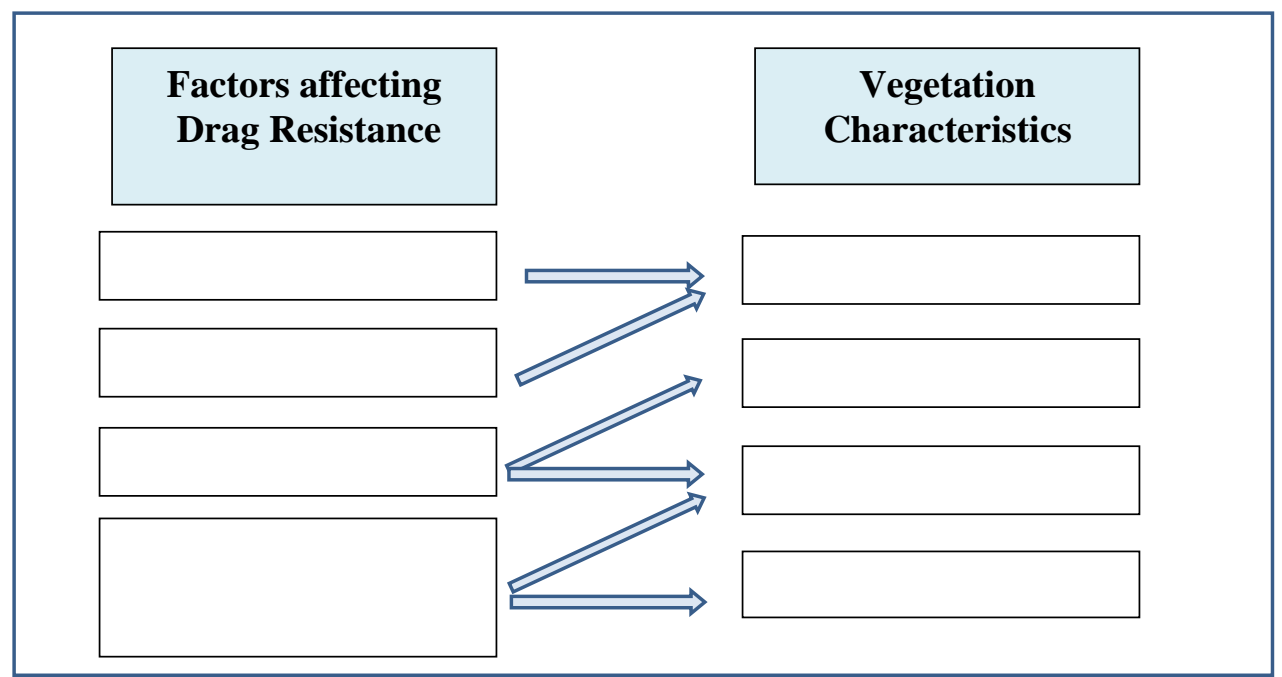

Figure 1: Drag resistance and vegetation characteristics

\section{PHYSICAL MODEL STUDY}

Detailed experimental studies were conducted to assess energy dissipation characteristics in which the vegetation was represented by geometrically similar small scale (approximately 1:100) models. Similar to preliminary studies, this study was conducted in a hydraulic flume of length $10 \mathrm{~m}$, width $30 \mathrm{~cm}$ and depth $30 \mathrm{~cm}$ and the energy dissipation of flow through vegetation was determined under steady flow conditions. The experimental set up is shown in Figure 2(a) and Figure 2(b).

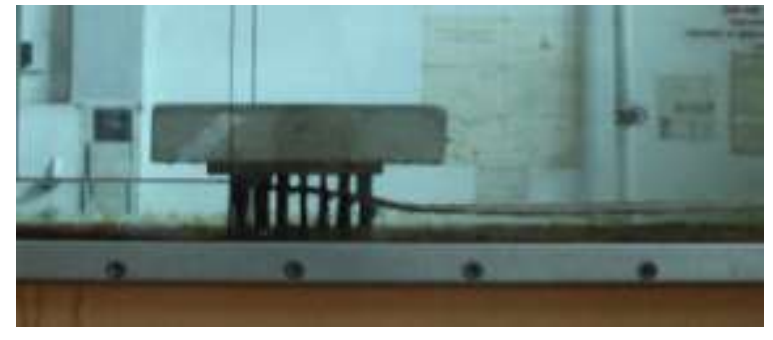

Figure 2(a): Experimental set-up

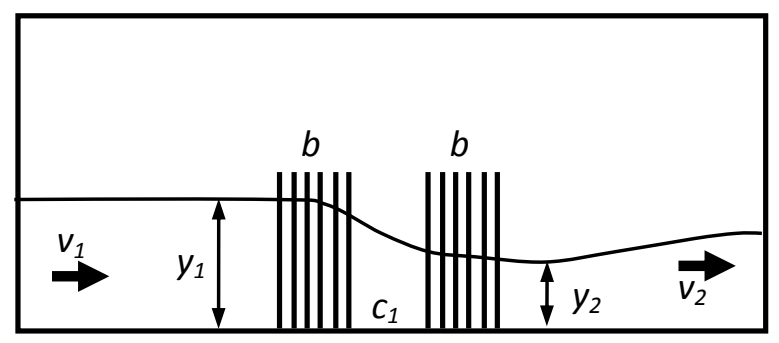

Figure 2(b): Experimental set-up

The inundation of the stem of plants without the aerial root system (Category I), perhaps representing the most common type of coastal vegetation, was considered in the tests where plants were represented by $4 \mathrm{~mm}$ diameter nails.

For the steady flow shown in Figure 2(b), neglecting frictional head loss and the bed slope, the head loss due to the presence of vegetation $d H$ can be expressed as:

$$
d H=H_{1}-H_{2}=\left(y_{1}-y_{2}\right)+\frac{1}{2 g}\left(V_{1}^{2}-V_{2}^{2}\right)
$$

Where, $H_{l}=$ total head upstream of vegetation

$$
H_{2}=\text { total head downstream of vegetation }
$$$$
y_{1}=\text { upstream depth of flow }
$$ 


$$
\begin{aligned}
& y_{2}=\text { downstream depth of flow } \\
& V_{l}=\text { upstream velocity of flow } \\
& V_{2}=\text { downstream velocity of flow } \\
& g=\text { acceleration of gravity }
\end{aligned}
$$

By replacing the velocity terms with discharge;

$$
d H=\left(y_{1}-y_{2}\right)+\frac{Q^{2}}{2 g B^{2}}\left[\frac{1}{y_{1}^{2}}-\frac{1}{y_{2}^{2}}\right]
$$

Where, $Q=$ rate of flow

$$
B=\text { width of the flume }
$$

Hence the energy loss can be determined by $\%$ head loss with respect to total head of incoming flow $H_{l}$, by depth and discharge measurements.

\section{RESULTS AND ANALYSIS}

Tests were considered for a number of vegetation configurations and the results are summarized in Table 2 . The comparison of results with preliminary unsteady flow test results for same vegetation configurations was also presented where $d R / R_{0} \%$ represents the $\%$ reduction in inundation distance over a sloping surface due to existence of vegetation.

As indicated in Table 2, with significant energy dissipation levels reaching $30 \%$ in parallel with reduction levels of inundation extent reaching $40 \%$, it is evident that vegetation is effective in mitigating adverse impacts of tsunami inundation. The dependence of reduction of inundation extent on energy dissipation by coastal vegetation is clearly evident in Figure 3. 
Table 2: Physical model test results

\begin{tabular}{|c|c|c|c|c|c|c|c|}
\hline Test & $b_{1}(\mathrm{~cm})$ & $c_{1}(\mathrm{~cm})$ & $b_{2}(\mathrm{~cm})$ & $\begin{array}{c}\text { Spacing } \\
(\mathrm{cm})\end{array}$ & $\begin{array}{c}\text { Pattern } \\
U / S\end{array}$ & $d H / H_{1} \%$ & $d R / R_{0} \%$ \\
\hline 1 & 15 & 0 & 0 & 2 & $U$ & 13.6 & 26.2 \\
\hline 2 & 15 & 0 & 0 & 2 & $S$ & 18.7 & 32.2 \\
\hline 3 & 30 & 0 & 0 & 2 & $U$ & 22.2 & 32.9 \\
\hline 4 & 30 & 0 & 0 & 2 & $S$ & 28.1 & 36.3 \\
\hline 5 & 15 & 10 & 15 & 2 & $U$ & 22.6 & 35.0 \\
\hline 6 & 15 & 10 & 15 & 2 & $S$ & 27.4 & 37.3 \\
\hline 7 & 15 & 0 & 0 & 3 & $U$ & 7.3 & 14.5 \\
\hline 8 & 15 & 0 & 0 & 3 & $S$ & 9.4 & 18.8 \\
\hline 9 & 30 & 0 & 0 & 3 & $U$ & 11.3 & 22.9 \\
\hline 10 & 30 & 0 & 0 & 3 & $S$ & 14.4 & 27.3 \\
\hline 11 & 15 & 10 & 15 & 3 & $U$ & 12.9 & 21.8 \\
\hline 12 & 15 & 10 & 15 & 3 & $S$ & 14.5 & 29.0 \\
\hline 13 & 15 & 0 & 0 & 4 & $U$ & 3.8 & 8.5 \\
\hline 14 & 15 & 0 & 0 & 4 & $S$ & 4.9 & 13.5 \\
\hline 15 & 30 & 0 & 0 & 4 & $U$ & 9.0 & 17.0 \\
\hline 16 & 30 & 0 & 0 & 4 & $S$ & 9.3 & 20.1 \\
\hline 17 & 15 & 10 & 15 & 4 & $U$ & 9.2 & 14.0 \\
\hline 18 & 15 & 10 & 15 & 4 & $S$ & 9.6 & 22.0 \\
\hline & & & & & & & \\
\hline
\end{tabular}

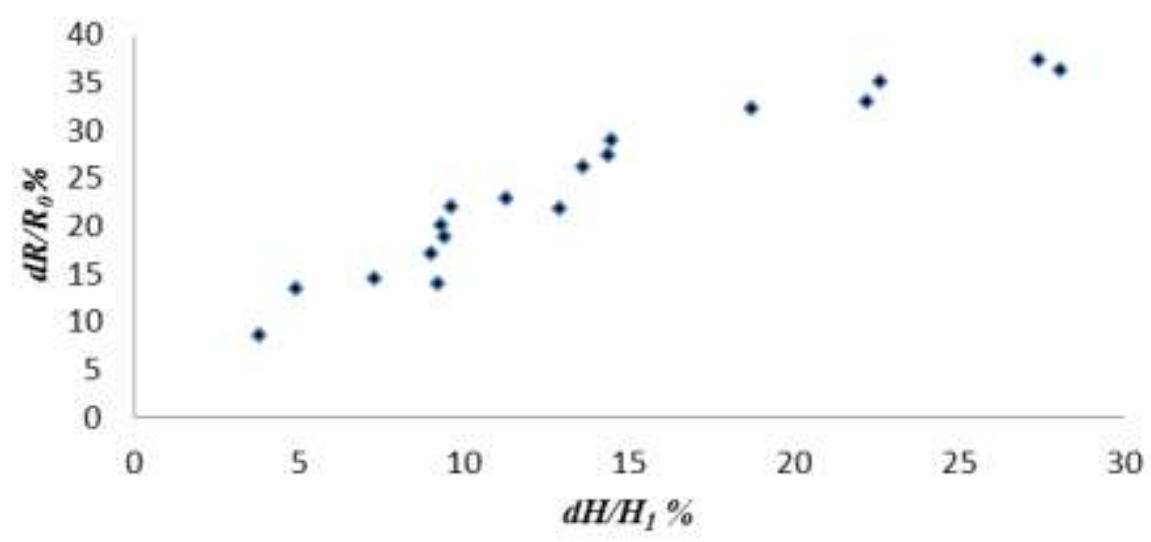

Relative influence of the various characteristics of the vegetation can be assessed by comparing the results of relevant model tests. The comparison of tests (1, 7 and 13), (3, 9 and 
15) and $(5,11$ and 17) reveals the influence of tree density and thickness of the vegetation belt on energy dissipation as shown in Figure 4.

Two grid patterns of vegetation, staggered and uniform have been considered in testing in order to represent the irregular pattern of naturally grown vegetation and regular pattern in plantations. The Figure 5 reveals that the higher levels of energy dissipation occurred with staggered pattern of vegetation, possibly due to high levels of flow interception than uniform pattern, indicating the significance of natural coastal vegetation belts.

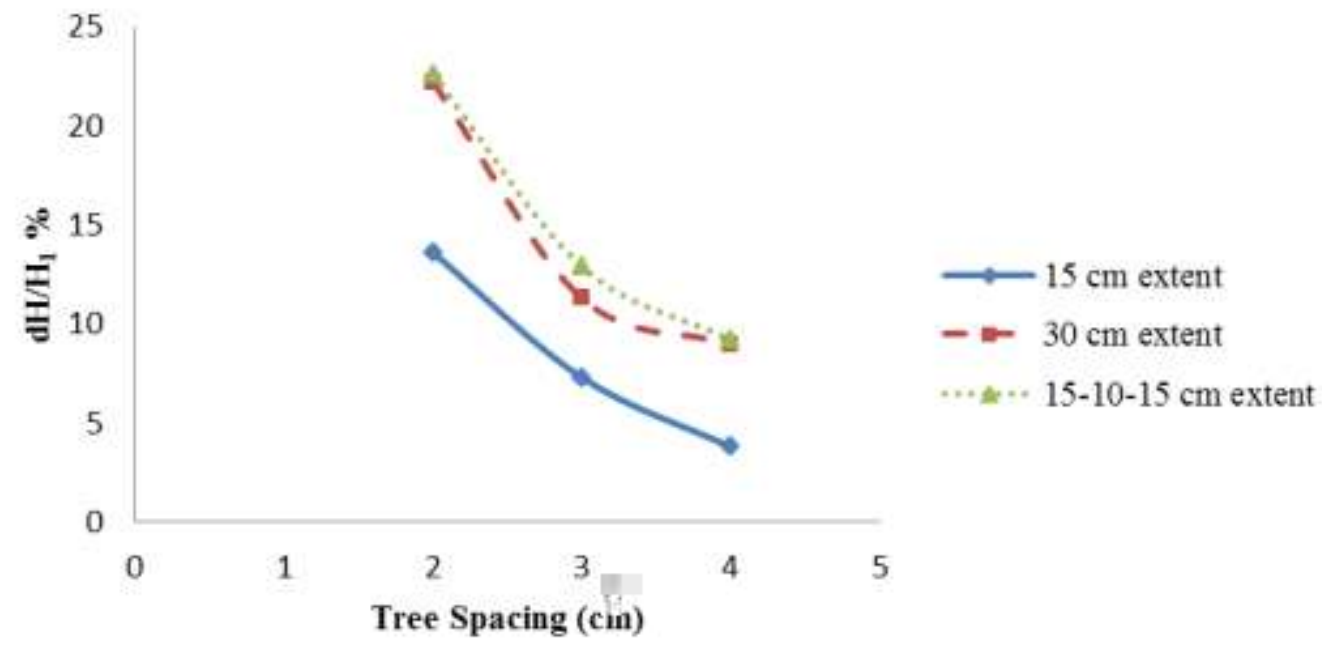

Figure 4: Effect of Tree Density and Extent of Vegetation

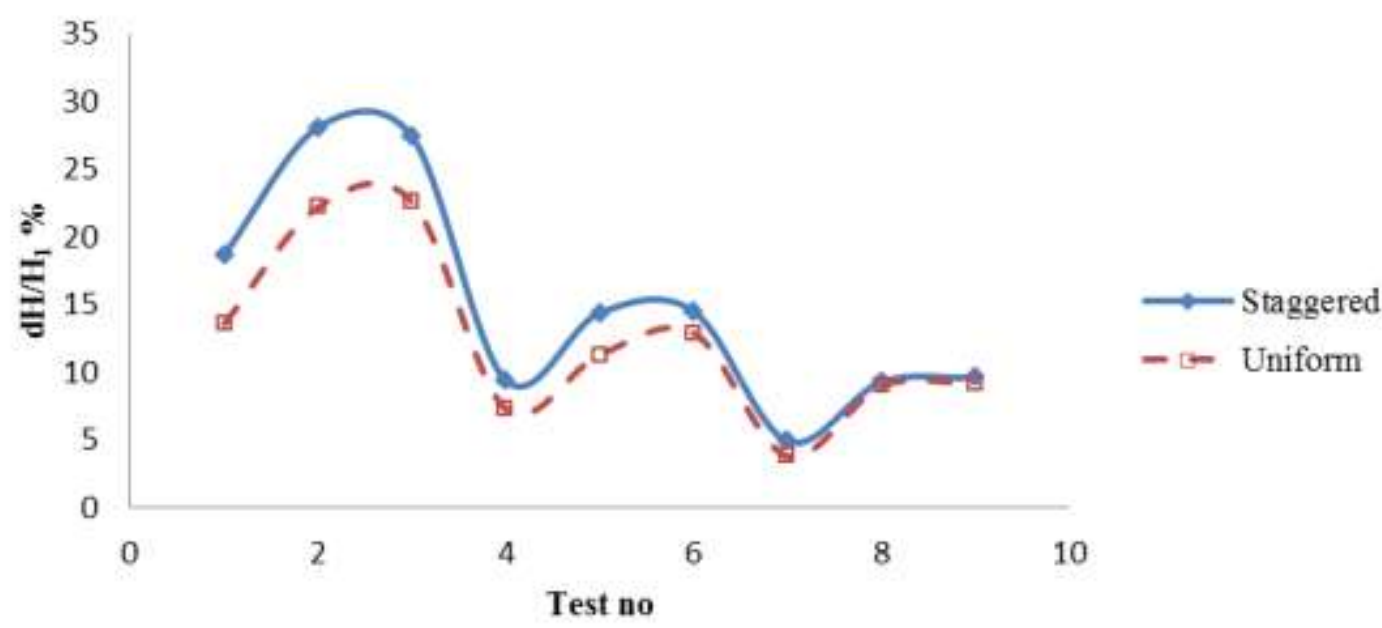

\section{CONCLUSION}

The results of an investigation carried out by using small scale physical models under steady flow conditions to assess the effectiveness of coastal green belts in mitigating impact and energy dissipation of tsunami overland flow are presented. significant levels of energy dissipation and reduction in inundation extent were observed through experimental studies and relative influence of vegetation characteristics in impact mitigation such as extent, spacing/density and distribution pattern were identified by the study. 
In spite of the restrictions imposed by the small scale used in the tests, the results are expected to provide useful guidance on the effective use of coastal green belts as a possible tsunami impact mitigation measure.

\section{REFERENCES}

Tanaka, N., Sasaki, Y., Mowjood, M.I.M. and Jinasena, K.B.S.N., (2007), Coastal vegetation structures and their functions in tsunami protection: Experience of recent Indian Ocean Tsunami, Landscape and Ecology engineering, 3, pp.33-4.

Ratnasooriya, A. H. R., Samarawickrama, S. P., Hettiarachchi, S.S.L., Bandara, R. P. S. S. and Tanaka, N., Mitigation of Tsunami Inundation by Coastal Vegetation, "Engineer", Journal of the Institution of Engineers, Sri Lanka, October 2008. 